\title{
Vulnerability of Machu Picchu citadel 100 years after its scientific discovery
}

\author{
C. Cuadra \\ Akita Prefectural University, Japan
}

\begin{abstract}
In the year 2011, Peru celebrates 100 years since Hiram Bingham discovered the citadel of Machu Picchu. The Inca citadel of Machu Picchu has become the most famous historical site in Peru; the site was declared as world cultural heritage by UNESCO in 1983 and also as one of the New Seven Wonders of the World in 2007. All of its constructions are made of stone masonry, and during almost four centuries the citadel endured and survived under a thick rain forest, until it was discovered in 1911. This paper attempts to describe mainly the seismic vulnerability by observing the structural conditions of historical stone buildings which are located in the citadel. The Andean region of Peru corresponds to a zone of low seismic activity however, these low intensity earthquakes could produce damage in the stone constructions. Moreover, the present structural conditions of some buildings lead one to think that these constructions have been subjected to the action of past earthquakes or other geodynamic actions. The characteristics of failures are discussed in this paper, through field survey, micro vibration measurements and dynamic analysis. The field survey on damage consisted of a detailed observation and evaluation of a group of selected buildings. Also, micro vibration measurements were performed on the ground and on some buildings to estimate their dynamic characteristics.

Keywords: stone masonry, world heritage, structural damage, seismic hazard.
\end{abstract}

\section{Introduction}

About 500 years ago, the Inca culture reached the peak in its development, which was just before the arrival of Spaniard conquistadors. By this time, the Incas had integrated a vast empire that stretched from the Maule River in Chile to northern Ecuador along the western side of the Andes Mountains. This territory, as in 
present days, had been continuously exposed to natural disasters such as excessive rainfall, earthquakes, landslides, floods, etc. In spite of such impending disasters, the Incas were able to develop techniques of construction to withstand such natural forces. The awe-inspiring cities and road networks that remain intact to this day serve as witness to their acumen in construction. The Inca citadel of Machu Picchu is the most famous historical site in Peru; a site declared as world cultural heritage by UNESCO in 1983 and also as one of the New Seven Wonders of the World in 2007. All of its constructions were made of stone masonry. The citadel was constructed by Inca Pachacutec and was abandoned after the Inca Empire collapsed by the year 1540 AD. During almost four centuries, the citadel endured and survived under a thick rain forest, until it was discovered by Hiram Bingham in 1911. However, it is important to analyze the probable causes of structural damage of the constructions to preserve them. To evaluate the current structural conditions of the buildings, the characteristics of failures are discussed in this paper, through field survey. The field survey on damage consisted of a detailed observation and evaluation of a group of selected buildings. It was observed that for a specific soil condition, the failure in some buildings could be the result of the action of past earthquakes. The structural system of Inca constructions involve various types, including adobe (sun-dried clay bricks), roughly shaped stones lay down with mud mortar, and finely shaped stones. They also used mud and clay as mortar for surface finishing. Finely shaped stone masonry was used for important building like temples, administrative structures and king's residences. In this type of construction, the adjacent stones are carefully shaped and fit snugly against each other without the use of mortar. In Machu Picchu citadel the remaining buildings are all made of stones.

\section{Target buildings and evaluation method}

Machu Picchu citadel is divided into two zones, the Agricultural Zone and the Urban Zone. In this research a group of stone constructions located in the "Urban sector" of Machu Picchu is analyzed to evaluate the structural condition of buildings. Some buildings are made of stone masonry laid with mud mortar and others are constructions made of fined shaped stone blocks without mortar. For the structural survey, an evaluation sheet was prepared to record the characteristics of each building and describe its structural condition. This survey has permitted to establish that different level of damage can be observed in the stone constructions. In Figures 1 to 5 some data sheets are shown, where main observations of the evaluation are written. It is inferred that some type of damage could be consequence of the action of previous earthquake. Damage due to settlement of underlying ground were also observed. Special attention is focused on two building that are located in a terrace called sacred square. These buildings are presented in Figures 4 and 5 and are called Temple of the Three Windows and Main Temple respectively. Both buildings were selected for ambient vibration measurements. 
Photo (1)
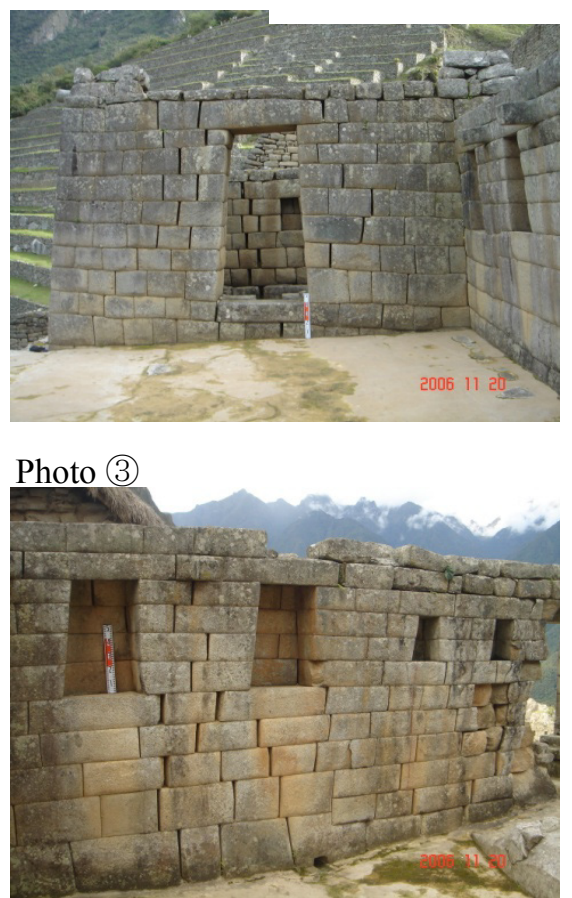

Type of structure: Fine shaped stone Location: Inclined ground Wall inclination: Slightly Damages on the upper part: Yes Collapse of walls: Partial Wall damages: Stone slip in 25 sites Gaps of $5 \sim 10[\mathrm{~mm}]: 4$ places Gaps of $10 \sim 15[\mathrm{~mm}]: 1$ place Gaps of $15 \sim 20[\mathrm{~mm}]: 6$ places Gaps of 20 25[mm]:5 places Gaps of more than 25[mm]: 9
Photo (2)

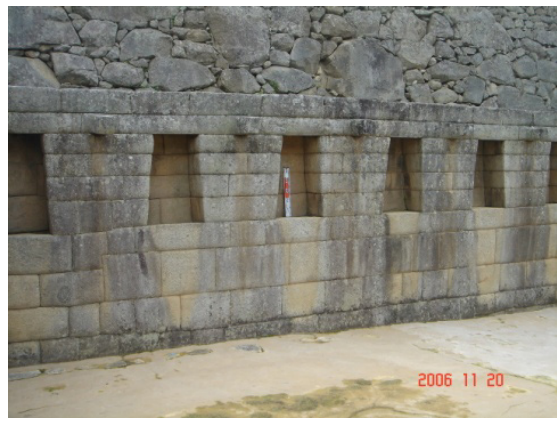

\section{Photo (4)}

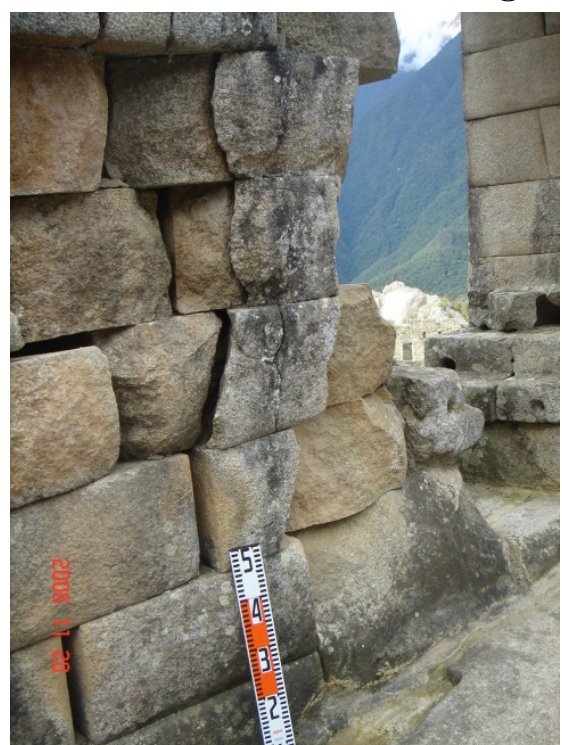

Figure 1: $\quad$ Damage evaluation at building no 2-4. 

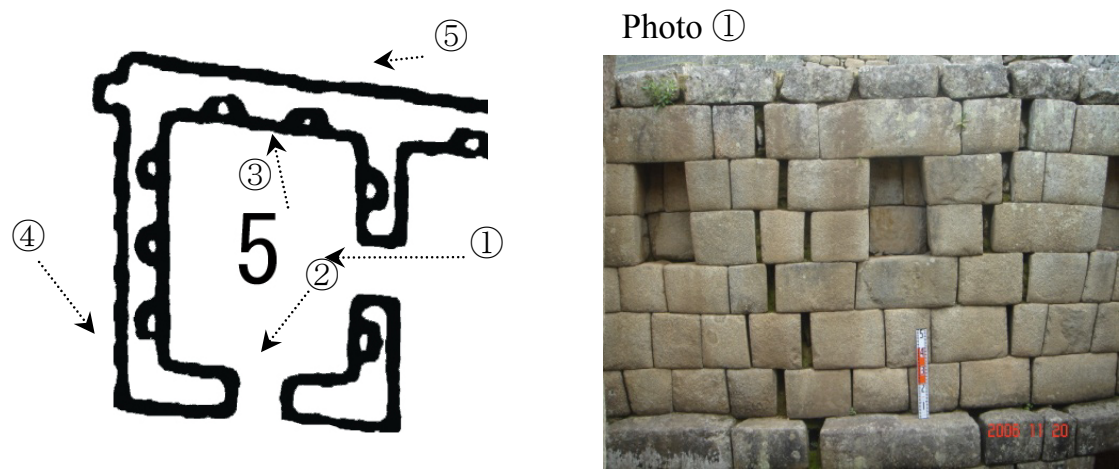

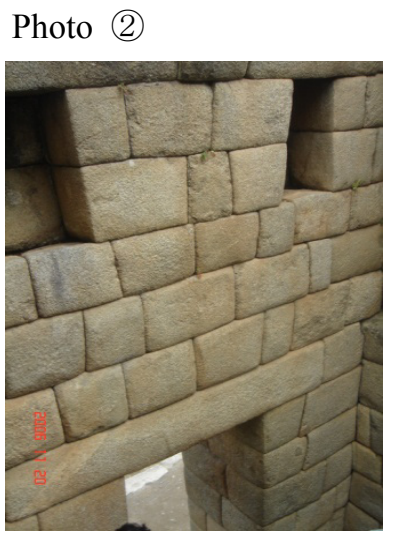

Photo (3)
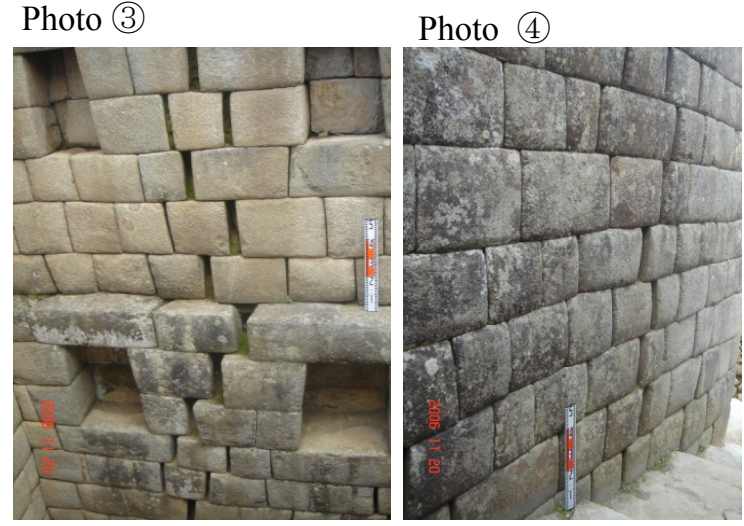

Type of structure: Fine shaped stone

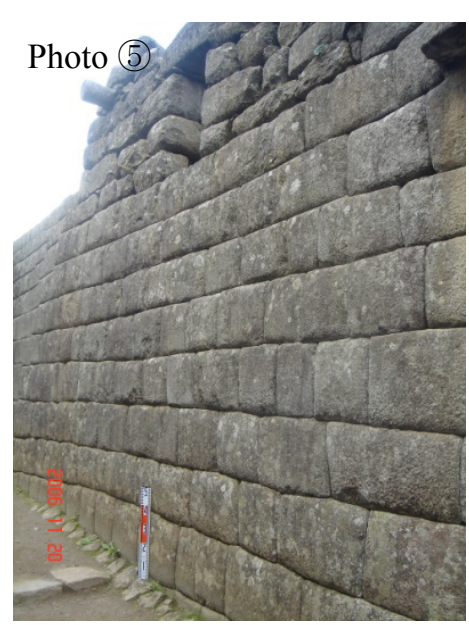
combined with stone laid with mud mortar Location: Inclined ground Wall inclination: Slightly Damages on the upper part: Yes Collapse of walls: Gable wall collapse Wall damages: Stone slip in 35 sites

Gaps of 10 15[mm]: 6 place

Gaps of 15 20[mm]:3 places

Gaps of 20 25[mm]: 1 places

Gaps of more than $25[\mathrm{~mm}]: 25$ places The construction apparently had triangular gable walls to form the roof of the buildings. These gable walls has collapsed and it is believed that the overturning was due to the action of horizontal force acting perpendicularly to the wall plane.

Figure 2: $\quad$ Damage evaluation at building no 2-5. 


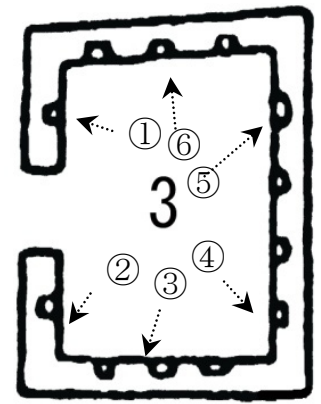

Photo (2)
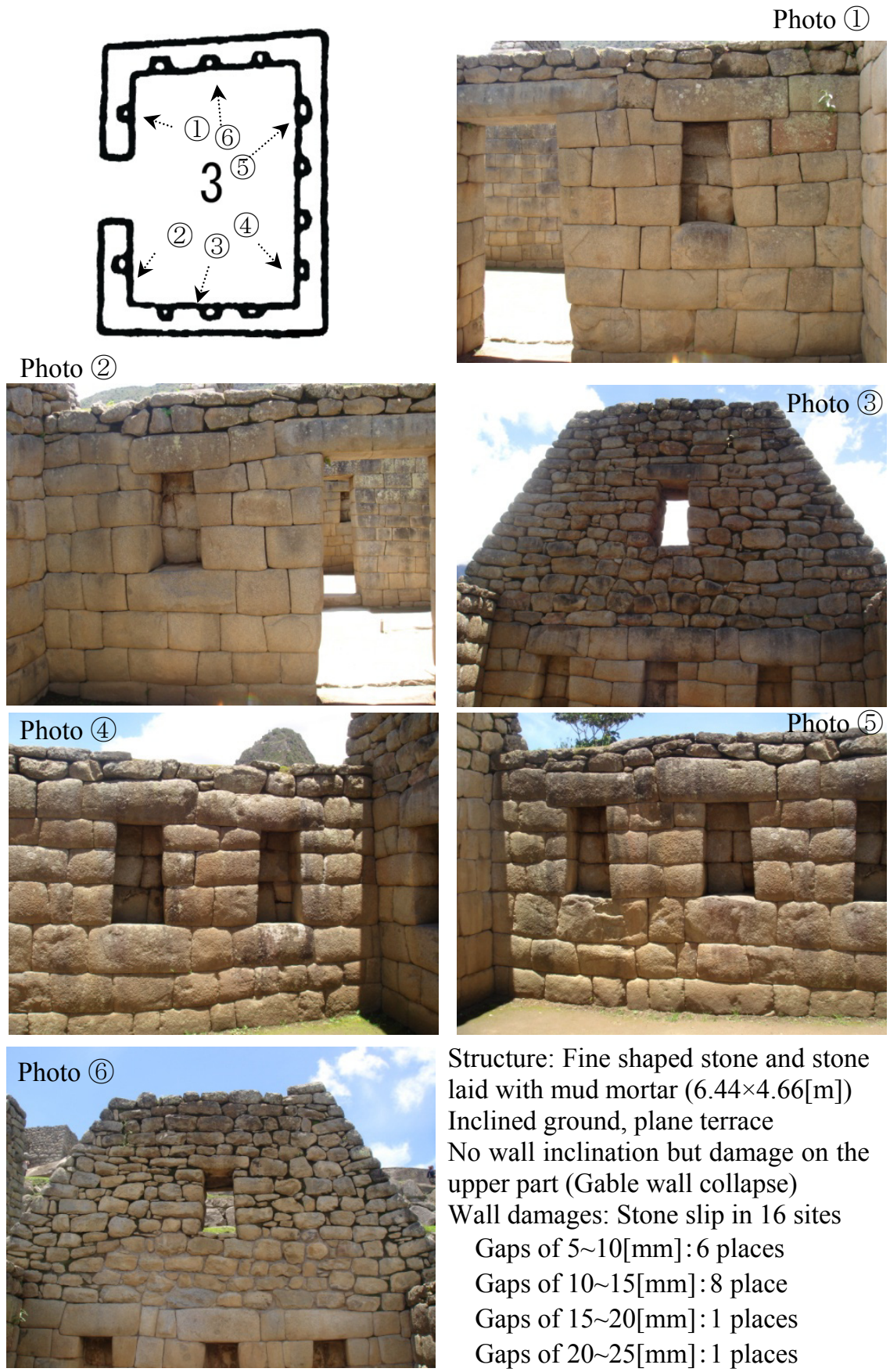

Structure: Fine shaped stone and stone laid with mud mortar $(6.44 \times 4.66[\mathrm{~m}])$ Inclined ground, plane terrace No wall inclination but damage on the upper part (Gable wall collapse) Wall damages: Stone slip in 16 sites

Gaps of $5 \sim 10[\mathrm{~mm}]: 6$ places

Gaps of 10 15[mm]:8 place

Gaps of 15 20[mm]: 1 places

Gaps of 20 25[mm]: 1 places

Figure 3: $\quad$ Damage evaluation at building no 3-3. 


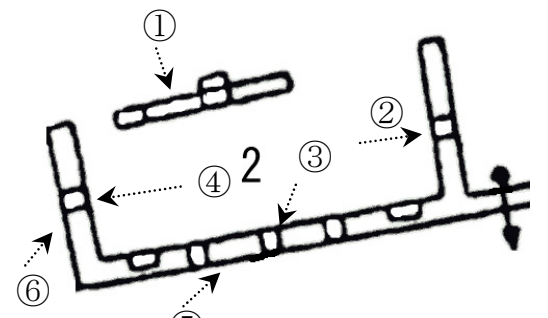

(5)
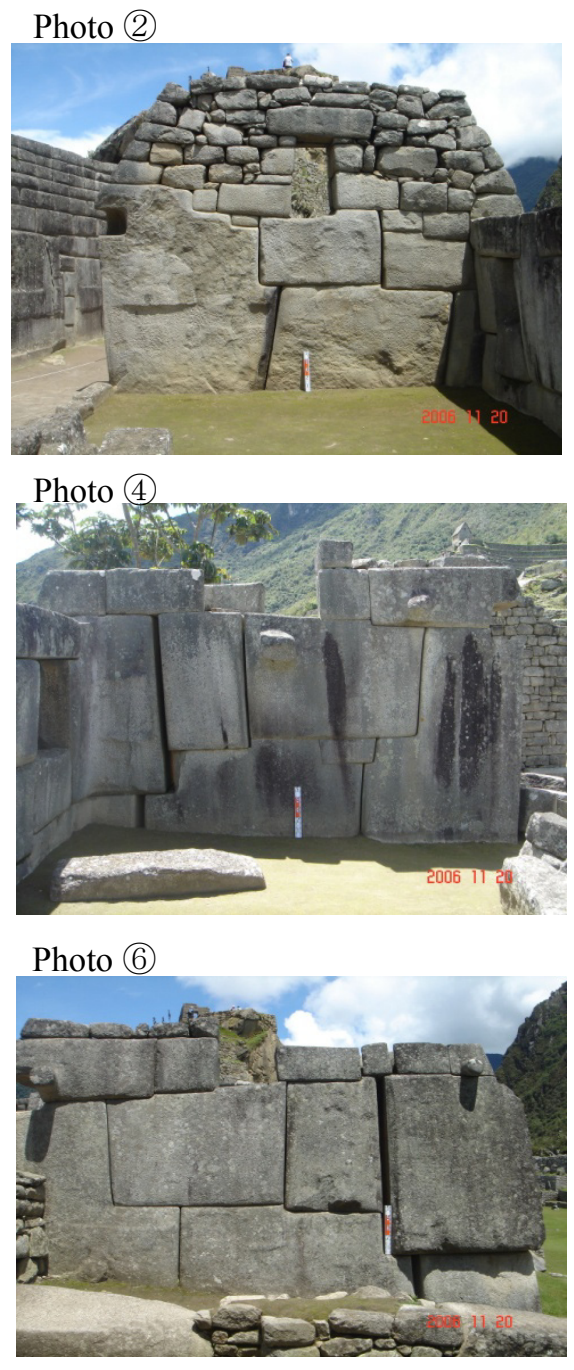
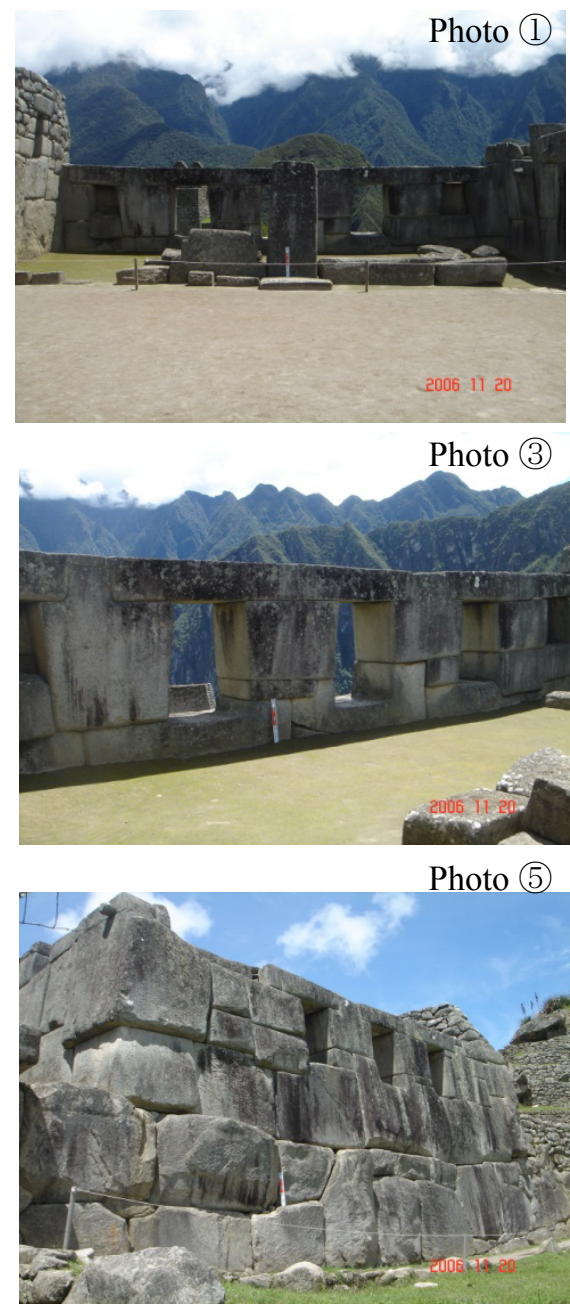

Type of structure: Fine shaped stone Dimensions: $4.53 \times 10.4[\mathrm{~m}]$ Location: Hill terrace Wall inclination: Slightly Damages on the upper part: Yes Collapse of walls: Partial Wall damages: Stone slip in 12 sites Horizontal slips of big stone blocks could be due to the action of past earthquakes

Figure 4: Damage evaluation at building no 4-2 (temple of the 3 windows). 

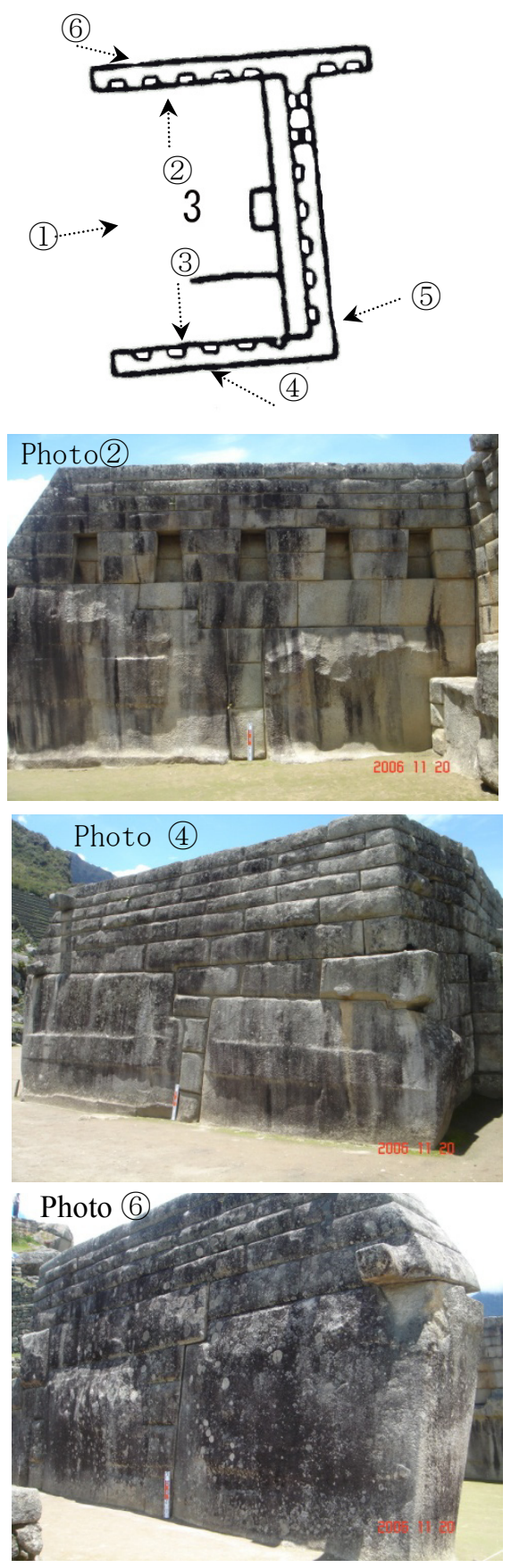
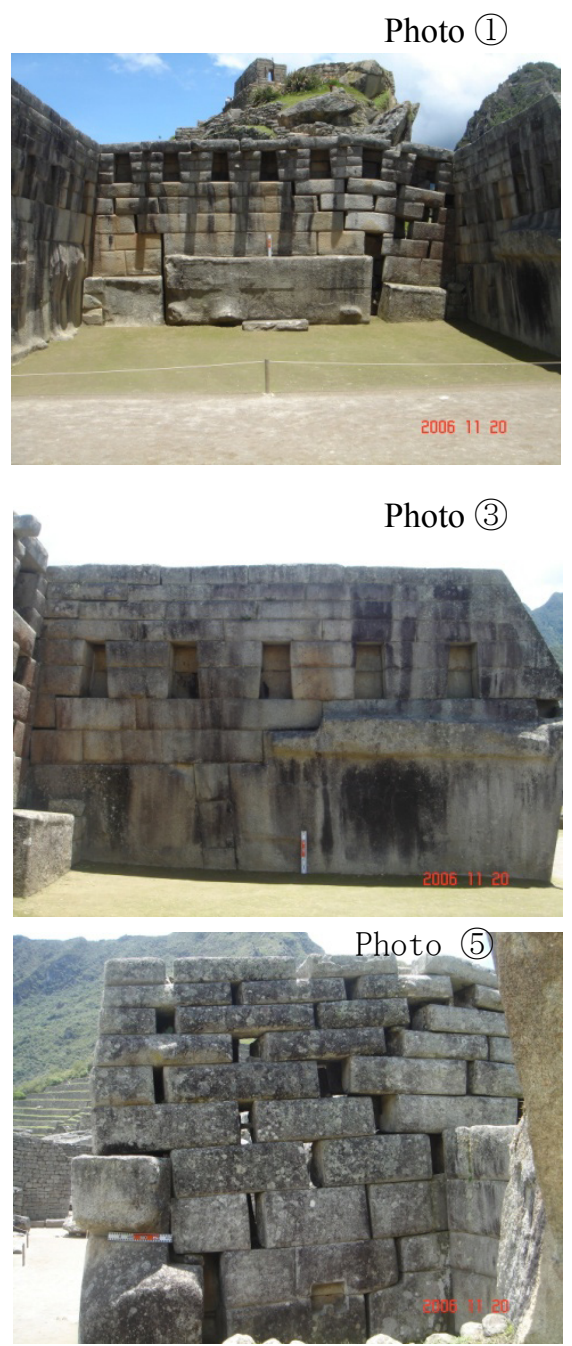

Type of structure: Fine shaped stone Dimensions: $6.40 \times 7.95[\mathrm{~m}]$

Wall inclination: Slightly Damages on the upper part: Yes Collapse of walls: Partial Wall damages: Stone slip in 36 sites

Gaps of $25 \sim 50[\mathrm{~mm}]: 11$ places Gaps of 50 100[mm]: 7 places Gaps of 100 200[mm]: 13 places Gaps of 200 300[mm]:5 places

Figure 5: Damage evaluation at building no 4-3 (main temple). 


\section{Ambient vibration measurements}

The Main Temple and the Temple of the Three Windows are located in the Sacred Plaza sector which is a terrace. Details of the Temple of the Three Windows and Main Temple are presented in Figures 4 and 5. The Main Temple shows damage of displacements between stone blocks of the north wall due to the settlement of the east wall. In the case of the Temple of the Three Windows, relative horizontal displacements of stone blocks can be observed.

Microtremor measurements were performed in the Main Temple and in the Temple of the Three Windows. In the case of the Main Temple, 3 transducers (two horizontal component sensors and one vertical component sensor) were set at the top of wall and at the ground level, respectively. For the Temple of the Three Windows, only horizontal component sensors were set on the structure and over the ground.

Figure 6 shows the $\mathrm{H} / \mathrm{V}$ spectral ratio obtained from microtremor measurements at the ground of Sacred Plaza. A predominant frequency of 23.7 $\mathrm{Hz}$ was estimated, which would mean that depth of the bedrock is shallow. Usually, the natural frequency of the ground ranges between $1 \mathrm{~Hz}$ for soft soil deposits and $10 \mathrm{~Hz}$ for hard soil deposits. Therefore, the estimated predominant frequency of $23.7 \mathrm{~Hz}$ indicates that the thickness for soft soil layer would be very thin (around $1 \mathrm{~m}$ ) and that the bedrock would be close to the ground surface. In consequence, these buildings would be founded directly on the bedrock. Therefore the apparent soil settlement failure observed Figure 5 would correspond to a failure or rupture of the underlying rock.

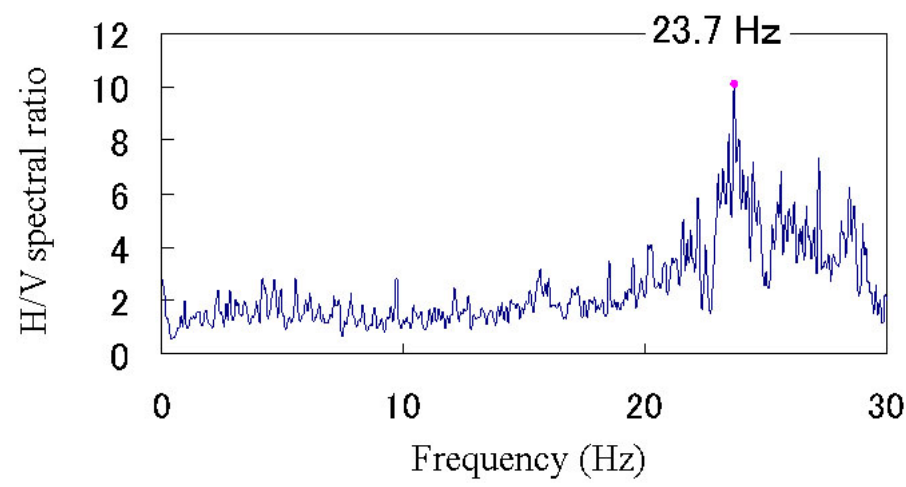

Figure 6: $\quad \mathrm{H} / \mathrm{V}$ spectral ratio at the ground of sacred plaza.

In the case of the Temple of the Three Windows, two horizontal components in NS direction and EW direction were measured, separately. Two sensors were located at the ground near building; one at the external ground (Ch. 9) and another sensor at the inner ground (Ch. 6) of the building. Also, one sensor was located at the central window (Ch. 8) and another sensor at the top of the building (just above the central window) (Ch 7). Figure 7 displays the locations of observation points. 


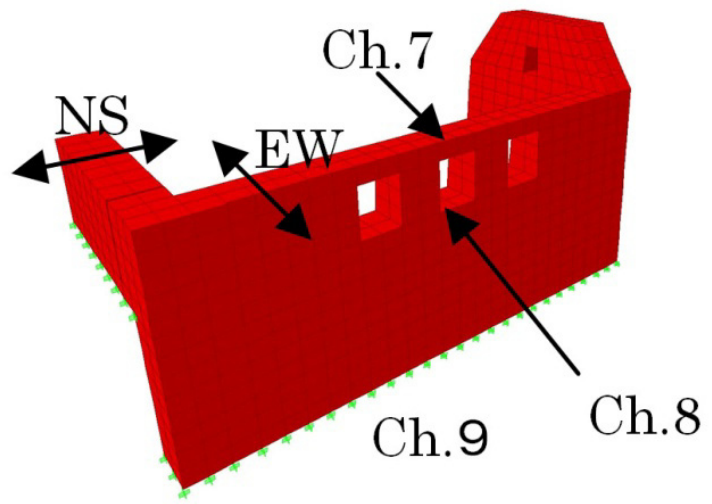

Figure 7: $\quad$ Micro vibration measurements at the temple of three windows.

To estimate the dynamic characteristics of the Temple of the Three Windows, the transfer functions between Ch. 9 and Ch. 7 and between Ch. 8 and Ch. 7 were computed, which results along the EW direction are shown in Figure 8. According to these results, the predominant frequencies of the west wall is 6.84 $\mathrm{Hz}$ when considering the transfer function from the external ground surface to the top of the wall (Ch. $7 / \mathrm{Ch}$. 9). When the transfer function from the inner
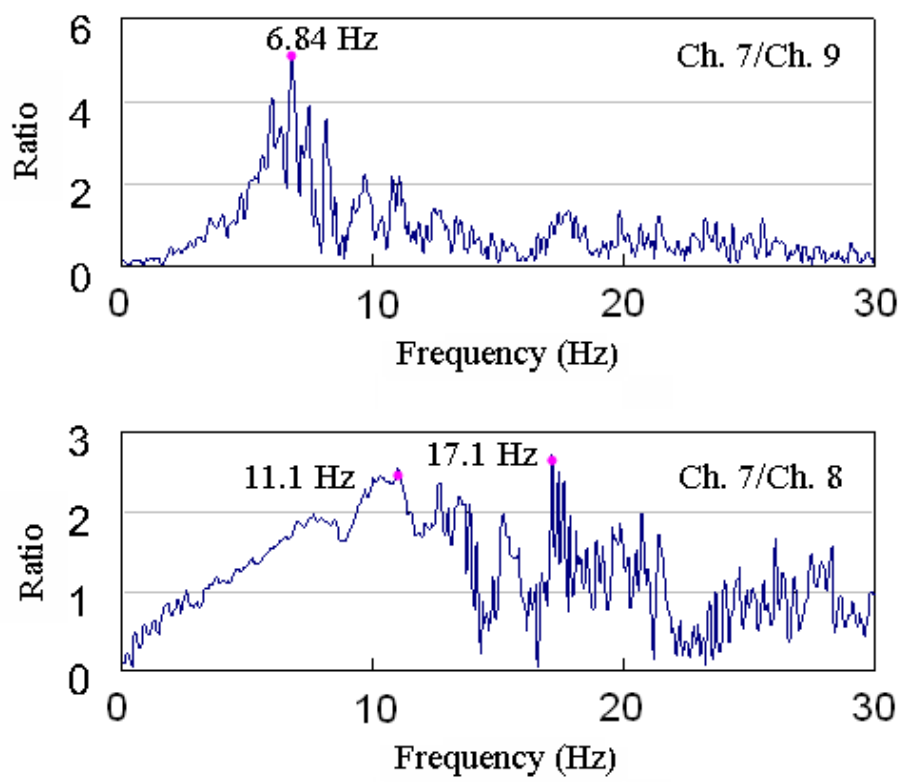

Figure 8: $\mathrm{H} / \mathrm{V}$ spectral ratio in the temple of the three windows (EW direction). 
ground surface to the top of the wall is considered, the predominant frequency is 17.1 Hz (Ch. 7/Ch. 8).

\section{Finite element model}

Since the ground levels of the external side and the inner side of the Temple of the Three Windows are different, two models were considered in the FEM analysis. The first model assumes that the east wall does not have contact with the inner ground, as shown in Figure 9(a). The second model considers that the wall is restrained by the inner ground, as shown in Figure 9(b). The walls were modeled using solid elements, and the elastic linear analysis was applied to compare the results with those obtained by micro vibrations. The appropriate value of the modulus of elasticity was determined by inverse analysis of the values of predominant frequencies estimated from transfer functions of micro vibration measurements. As equivalent elastic modulus a value of $1.3 \mathrm{kN} / \mathrm{mm}^{2}$ was obtained, which gives good agreements between proper frequencies from FEM and predominant frequencies from micro vibration measurements. Table 1 shows the comparison of both results.

Table 1: $\quad$ Vibration modes for the temple of the three windows $(\mathrm{Hz})$.

\begin{tabular}{|l|l|l|}
\hline Mode & Micro vibrations & FEM \\
\hline $\begin{array}{l}1^{\text {st }} \text { Mode } \\
\text { (Model of Figure 9(a)) }\end{array}$ & 6.84 & 6.93 \\
\hline $\begin{array}{l}2^{\text {nd }} \text { Mode } \\
\text { (Model of Figure 9(b)) }\end{array}$ & 17.10 & 17.30 \\
\hline
\end{tabular}
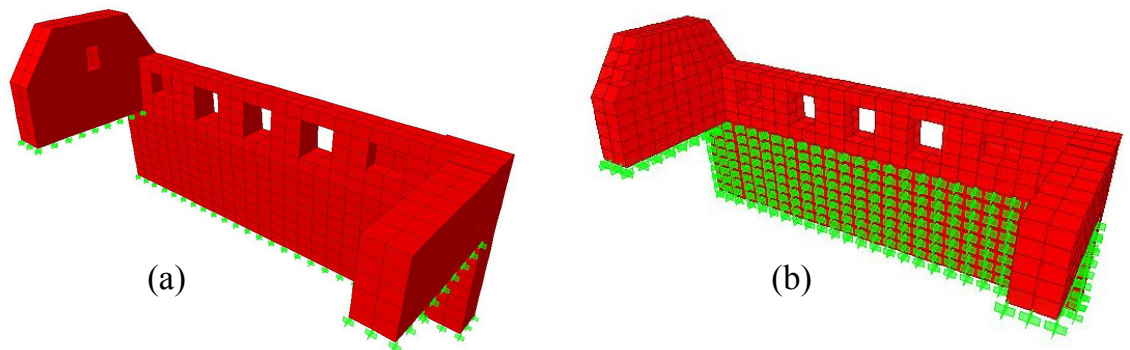

Figure 9: $\quad$ FEM models considered for the temple of the three windows.

The equivalent modulus of elasticity obtained for the polygonal shaped stone masonry, which is the case of the Temple of the Three Windows, is between the equivalent modulus of $0.9 \mathrm{kN} / \mathrm{mm}^{2}$ (for roughly shape stone masonry) and the equivalent modulus of $1.8 \mathrm{kN} / \mathrm{mm}^{2}$ (for rectangular shaped stone masonry). The smaller value for roughly shaped masonry can be explained due that mud mortar is used. Larger equivalent elastic modulus for polygonal stone masonry could be expected, but according to the results, larger equivalent elastic modulus for rectangular fine shaped stone masonry was obtained. 
Finally, it is important to remark that the horizontal sliding between stone blocks in the Temple of the Three Windows could be the consequence of strong seismic forces of past earthquakes.

\section{Conclusions}

A field survey has been performed on a selected part of Machu Picchu citadel to evaluate the structural condition of historical constructions. Damage was detected in many buildings and an evaluation to establish the causes of this damage was done in this research. As examples of this evaluation results of selected buildings are shown.

Slips of stone blocks are observed as gaps between adjacent blocks in stone masonry walls. In some cases the movement of blocks could be due the settlement of the underlying ground. However, in some cases there is not ground settlement and therefore it is supposed that the movement of blocks could be the result of the action of past earthquakes.

Probable action of past earthquakes on the failure of these buildings or portion of these historical buildings can be inferred from the observation of the structural condition of gables walls. Most of them have collapsed and from detailed observation of apparently undamaged walls it can be observed that most of them have been reconstructed.

The evaluation of the settlement observed in the Main Temple (Building No 4-3) conduces to think that it is probably due to the fracture of the subjacent bedrock in which the building is founded. Apparently, the bedrock is very sallow and the fracture of this rock can be explained only by the action of large geodynamic forces.

The particular horizontal sliding between stone blocks at one wall corner of the Temple of the Three Windows (Building No 4-2, Photo (6) could be the consequence of strong seismic forces of past earthquakes.

Microtremor measurements performed in two temples of the Sacred Plaza of Machu Picchu provided valuable information for evaluating the dynamic characteristics of Inca stone heritage structures.

The dynamic vibration modes of the Temple of the Three Windows were estimated from predominant frequencies of transfer functions of microtremor records. The equivalent elastic modulus was estimated by inverse analysis of vibration modes of two FEM models. According to the results, the equivalent elastic modulus of $1.3 \mathrm{kN} / \mathrm{mm}^{2}$ could represent an approximate value for polygonal shaped stone masonry.

\section{References}

[1] C. H. Cuadra, T. Saito, C. A. Zavala, \& M. A. Diaz (2010). The challenges of protect historical adobe constructions in Peru. $14^{\text {th }}$ European Conference in Earthquake Engineering, Ohrid, Macedonia. CD ROM Paper No.392. 
[2] Cardenas, L. \& Zavala, C. (2008) "Estudio de Vulnerabilidad Estructural del Hotel Comercio" (Study on Structural Vulnerability of Hotel Comercio), CISMID-UNI Report (in Spanish).

[3] C. Cuadra, Y. Sato, J. Tokeshi, H. Kanno, J. Ogawa, M. B. Karkee \& J. Rojas. Evaluation of the dynamic characteristics of typical Inca heritage structures in Machupicchu. Ninth International Conference on Structural Studies, Repairs and Maintenance of Heritage Architecture, STREMAH IX, Malta, Jun. 2005, pp. 237-244.

[4] M. B. Karkee, C. Cuadra, \& L. Sunuwar. The challenges of protecting heritage architecture in developing countries from earthquake disasters. Ninth International Conference on Structural Studies, Repairs and Maintenance of Heritage Architecture, STREMAH IX, Malta, Jun. 2005, pp. 407-419.

[5] C. Cuadra, M.B. Karkee, J. Ogawa, and J. Rojas. An evaluation of earthquake risk to Inca's historical constructions. Proceedings of the 13th World Conference on Earthquake Engineering, Vancouver, B.C., Canada, August 1-6, 2004, CD-ROM Paper No. 150.

[6] Sudhir R. Shrestha, Madan B. Karkee, Carlos H. Cuadra, Juan C. Tokeshi and S. N. Miller. Preliminary study for evaluation of earthquake risk to the historical structures in Kathmandu valley (Nepal). Proceedings of the 13th World Conference on Earthquake Engineering, Vancouver, B.C., Canada, August 1-6, 2004, CD-ROM Paper No. 172.

[7] J. Ogawa, C. Cuadra, M.B. Karkee, and J. Rojas. A study on seismic vulnerability of Inca's constructions. Proceedings of the 4th International Conference on Computer Simulation in Risk Analysis and Hazard Mitigation. Risk Analysis IV, Rhodes, Greece 2004, pp 3-12.

[8] C. Cuadra, M.B. Karkee, J. Ogawa, and J. Rojas. Preliminary investigation of earthquake risk to Inca's architectural heritage. Proceedings of the Fourth International Conference of Earthquake Resistant Engineering Structures, Ancona, Italy 2003, pp. 167-176.

[9] K. R. Wright and A. Valencia. Machu Picchu: A Civil Engineering Marvel. American Society of Civil Engineers ASCE PRESS, Reston Virginia, 2000.

[10] Sunuwar, L., Karkee, M., Tokeshi, J., and Cuadra, C. Applications of GIS in Probabilistic Seismic Hazard Analysis of Urban Areas. Proc. Of the Fourth International Conference of Earthquake Engineering and Seismology, Tehran, Iran, 2003.

[11] Thiel, C. Earthquake Damageability Criteria for Due Diligence Investigations. The Structural Design of Tall Buildings, 11, pp 233-263.

[12] Miranda, O., Gallardo, J., Cuadra, C. \& Ogawa, J. (2000) "Reduction of seismic damage in Peruvian traditional constructions" 2nd International Conference on Computer Simulation in Risk Analysis and Hazard Mitigation. Risk Analysis II, Bologna, Italy, Oct. 2000, pp. 389-396 